\title{
Hitch-hiking parasite: a dark horse may be the real rider
}

\author{
Kim N. Mouritsen* \\ Department of Marine Ecology, Institute of Biological Sciences, University of Aarhus, Finlandsgade 14, DK-8200 Aarhus N, Denmark
}

Received 3 April 2001; received in revised form 22 May 2001; accepted 22 May 2001

\begin{abstract}
Many parasites engaged in complex life cycles manipulate their hosts in a way that facilitates transmission between hosts. Recently, a new category of parasites (hitch-hikers) has been identified that seem to exploit the manipulating effort of other parasites with similar life cycle by preferentially infecting hosts already manipulated. Thomas et al. (Evolution 51 (1997) 1316) showed that the digenean trematodes Microphallus papillorobustus (the manipulator) and Maritrema subdolum (the hitch-hiker) were positively associated in field samples of gammarid amphipods (the intermediate host), and that the behaviour of Maritrema subdolum rendered it more likely to infect manipulated amphipods than those uninfected by M. papillorobustus. Here I provide experimental evidence demonstrating that $M$. subdolum is unlikely to be a hitchhiker in the mentioned system, whereas the lucky candidate rather is the closely related but little known species, Microphallidae sp. no. 15 (Parassitologia 22 (1980) 1). As opposed to the latter species, Maritrema subdolum does not express the appropriate cercarial behaviour for hitch-hiking. (C) 2001 Australian Society for Parasitology Inc. Published by Elsevier Science Ltd. All rights reserved.
\end{abstract}

Keywords: Microphallid trematodes; Transmission strategy; Cercarial behaviour; Maritrema subdolum; Microphallidae sp. no. 15

Parasites with complex life cycles (e.g. many helminths) often manipulate the behaviour of their host in order to facilitate inter-host transmission (Dobson, 1988; Moore and Gotelli, 1990; Poulin, 1994a, 1995). However, manipulation is likely to pose a cost on the manipulating parasite (Poulin, 1994b, 1995; Lafferty et al., 2000) and since several parasite species often coexist by having similar life cycles (e.g. Thomas et al., 1998a), there exists an inherent possibility that natural selection has favoured a "cheating-strategy' in which a non-manipulative parasite species preferentially infects host individuals already infected by a manipulating parasite with similar life cycle (Combes, 1991; Poulin, 1994b; Thomas et al., 1998a; Lafferty et al., 2000). This 'hitch-hiker' will thereby achieve the benefit of manipulation for a relatively low cost.

The hitherto best documented example of such apparently active hitch-hiking involves the microphallid trematodes, Microphallus papillorobustus (the manipulator) and Maritrema subdolum (the hitch-hiker) (see Thomas et al., 1997 and references therein). Both parasite species use mud snails (Hydrobia spp.) as first intermediate host in which they produce cercariae that leave the snail to penetrate the second

\footnotetext{
* Corresponding address. Department of Zoology, University of Otago, P.O. Box 56, Dunedin, New Zealand. Tel.: +64-3-479-7987; fax: +64-3479-7584.

E-mail address: kim.mouritsen@stonebow.otago.ac.nz (K.N. Mouritsen).
}

intermediate host (usually amphipods). Here they encyst as metacercariae, and when an infected amphipod is eaten by a shorebird (the final host), the metacercariae will develop into adult trematodes, producing eggs that leave the bird through the faeces. The life cycle is completed when the eggs are eaten by hydrobiids. After infecting the amphipod Gammarus insensibilis, M. papillorobustus metacercariae reverse the usual behaviour of this second intermediate host, inducing positive phototactism and negative geotactism. As a consequence, these manipulated amphipods often termed 'mad gammarids' - are significantly more exposed to trophic transmission than uninfected specimens because they will move towards the water surface and hence enter the microhabitat of aquatic birds, the final hosts. Whereas $M$. subdolum seems unable to induce a similar behavioural change in the gammarids, it does, however, co-occur with $M$. papillorobustus in the second intermediate host more often than would be expected by chance and Thomas et al. (1997) showed experimentally that M. subdolum cercariae were swimming in the upper part of a water column ( $26 \%$ were found $2 \mathrm{~cm}$ or more above the bottom) to a significantly larger extent than $M$. papillorobustus cercariae (14\%). It was therefore suggested that M. subdolum were swimming high in the water column in order to infect 'mad gammarids', i.e. actively hitch-hiking hosts initially infected and manipulated by $M$. papillorobustus.

Besides being an intriguing story, the phenomenon of 
hitch-hiking has important ecological and evolutionary implications, and hence, has received increasing empirical as well as theoretical attention (Lafferty and Morris, 1996; Thomas et al., 1998a-c; Lafferty, 1999; Poulin et al., 2000; Lafferty et al., 2000, and references therein). However, as the hunt for more hitch-hikers continues I wish to advocate for a more rigorous approach to the phenomenon. Firstly, because the systematics of many parasite taxa is often not very well unravelled, the identity of both parties involved (the manipulator and the hitch-hiker) should be considered very carefully. Otherwise, there will be more confusion than light cast upon the phenomenon. Secondly, because hitchhiker candidates so far have been identified largely based upon their positive association with a manipulating parasite from field samples, experimental evidence is badly needed.

Here I demonstrate that M. subdolum Jaegerskioeld, 1909 is an unlikely hitch-hiker of 'mad gammarids', whereas this term rather should be attached to Microphallidae sp. no. 15 (Deblock, 1980). The latter is a related and morphologically very similar species, whose biology is largely unknown, besides that it, like M. subdolum, exploits Hydrobia spp. as first intermediate hosts.

Mud snails (Hydrobia ulvae) were collected in August 1999 (experiment I) and May 2000 (experiment II) on an intertidal mudflat in the southern part of the Danish Wadden Sea $\left(54^{\circ} 56^{\prime} \mathrm{N} / 8^{\circ} 39^{\prime} \mathrm{E}\right)$. In the laboratory, trematode infected snails were identified according to the presence of cercarial emergence, and snails infected by the microphallid trematodes M. subdolum and Microphallidae sp. no. 15, were stored separately in aquaria supplied with seawater (15$20^{\circ} \mathrm{C}, 26 \%$ ) and sieved sediment. Identification of the two species of trematode larvae followed Deblock (1980) and was mainly based on the length and shape of their stylet (see Fig. 1A,B), observed and measured under a light microscope.

Experiment I: Ten M. subdolum infected snails and 10 Microphallidae sp. no. 15 infected snails were established according to the type of infection in two small Petri dishes supplied with $25^{\circ} \mathrm{C}, 26 \%$ seawater, and incubated for 30 min. A sample of about 10 released cercariae from each dish was inspected under the light microscope in order to confirm the identity of the released larval trematodes. Fifty M. subdolum cercariae and 42 Microphallidae sp. no. 15 cercariae were then transferred to a two-chambered 'sandwich-aquarium', one species in each chamber. The sandwich-aquarium was an 11-cm high, $13-\mathrm{cm}$ long and $0.4-\mathrm{cm}$ wide (inner measure) transparent aquarium mounted on a base. Each chamber contained a water column of $7.6 \mathrm{~cm}\left(20^{\circ} \mathrm{C}, 26 \%\right.$ ). Just in front of the sandwich-aquarium, a horizontally arranged stereomicroscope was placed through which the narrow water column and its content of swimming cercariae could be inspected. Prior to cercarial transfer, the sandwich-aquarium was covered by a lightproof box, open only from above, where a 60-W light source was placed. Hence, light could only enter the aquarium from above. After $3 \mathrm{~h}$, the lightproof box was removed and the number of cercariae in each of five water column intervals $(0-5,5-22,22-39,39-56$ and $56-73 \mathrm{~mm})$ was recorded in both chambers of the sandwich-aquarium. Since the swimming activity of larval microphallids usually starts decreasing $6-7 \mathrm{~h}$ post-release at about $20^{\circ} \mathrm{C}$ (K.N. Mouritsen, unpublished data), data were obtained at $3.5 \mathrm{~h}$ post-release, thereby excluding the possibility that a small difference in cercarial longevity between the two species affected the result.

Experiment II: Similar to experiment I, except that: (1) it was carried out at $22^{\circ} \mathrm{C}$ in a different but similarly designed sandwich-aquarium, (2) $100 \mathrm{M}$. subdolum and 110 Microphallidae sp. no. 15 cercariae were used and (3) the vertical distribution of the two species were recorded $4 \mathrm{~h}$ postrelease by counting the number of swimming cercariae in 1-cm intervals in the 9-cm high water column.

The difference between the vertical distribution in the water column of the two species of larval trematodes is highly significant (Two-sample Kolmogorov-Smirnov test, experiment I: $Z=2.86, P<0.001$; experiment II: $Z=6.31, P<0.001$; Fig. 1). Whereas cercariae of $M$. subdolum basically remained in the bottom $5-10 \mathrm{~mm}$ of the water column, specimens of Microphallidae sp. no. 15 were more evenly distributed, and 75 and $62 \%$ were recorded more than $2 \mathrm{~cm}$ above the bottom in experiments I and II, respectively.

The present results clearly demonstrate that cercariae of M. subdolum have a high affinity for the sediment-water interface as opposed to Microphallidae sp. no. 15 cercariae that express a more 'pelagic' swimming behaviour. The clear difference between the larval behaviour of the two species has been demonstrated repeatedly in my laboratory, and is now used as the standard initial step towards species identification of larval microphallid trematodes.

The behaviour of $M$. subdolum may be a consequence of either negative phototactism (light entered the experimental unit only from above) or positive geotactism. Since photoresponse in $M$. subdolum previously has been shown to be absent (Prokofyev, 1997), positive geotactism may be a likely explanation for the observed cercarial behaviour. Hence, $M$. subdolum appears well-adapted to reach especially bottom-dwelling secondary hosts, consistent with high prevalences and infection intensities of $M$. subdolum found among the benthic amphipod Corophium volutator in both field and laboratory studies (Mouritsen and Jensen, 1997; Meissner and Bick, 1997; Mouritsen et al., 1998).

Because the larvae of Microphallidae sp. no. 15 neither accumulated at the bottom nor at the surface of the water column, the species may be photo- and geotactically neutral. Distributed throughout the water column, these cercariae may be substantially better at infecting pelagic than benthic amphipods. At least, the transmission success to benthic corophiids is significantly lower for Microphallidae sp. no. 15 than for M. subdolum under similar experimental conditions (K.N. Mouritsen and S. Chinho, unpublished data).

Hence, M. subdolum larvae seem unlikely to be hitch- 


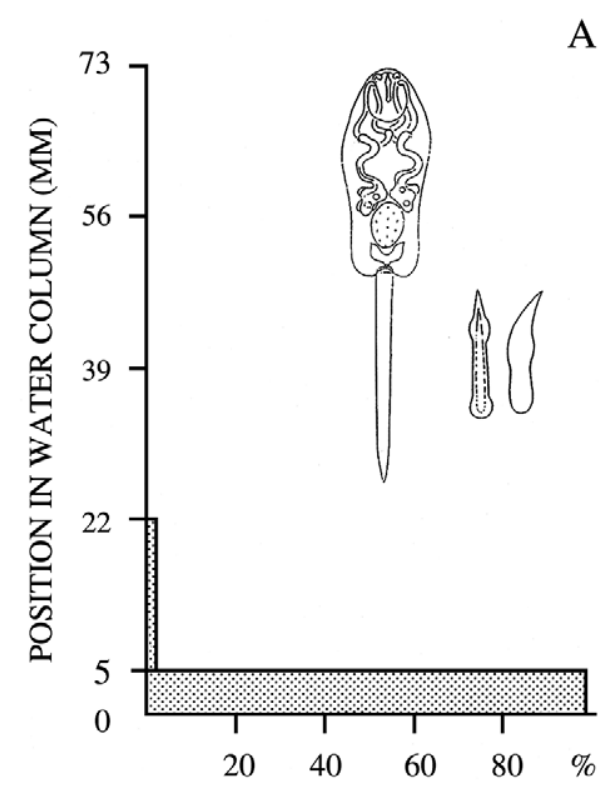

A

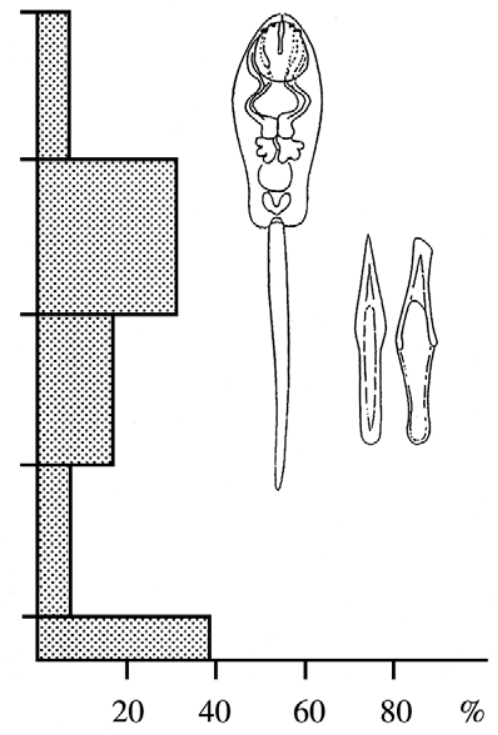

$\mathrm{C}$

$\mathrm{D}$
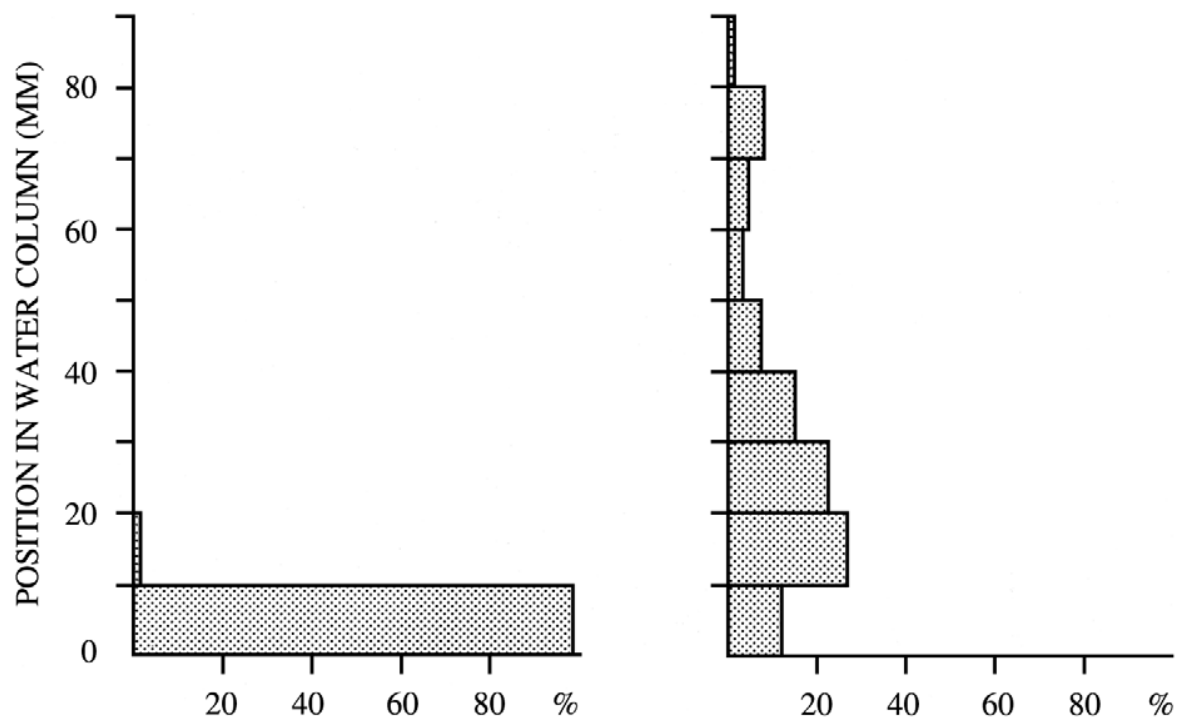

Fig. 1. (A,B) The vertical distribution of (A) M. subdolum $(n=50)$ and (B) Microphallidae sp. no. $15(n=42)$ cercariae in the water column from experiment I. Body/tail length: $M$. subdolum, 130-140/130-150 $\mu \mathrm{m}$, Microphallidae sp. no. 15, 120-150/110-140 $\mu \mathrm{m}$. Stylet lengths are 13-18 and 23-24 $\mu \mathrm{m}$, respectively. Note the difference in stylet shape between the two species. Left, dorsal view. Right, lateral view. Cercaria drawings and measures after Deblock (1980). (C,D) The vertical distribution of (C) M. subdolum $(n=100)$ and (D) Microphallidae sp. no. $15(n=110)$ cercariae in the water column from experiment II.

hikers of 'mad gammarids', as frequently stated. Microphallidae sp. no. 15, in contrast, appears to be a much more promising candidate. As emphasised, adaptive host-manipulation that increases trophic transmission is likely to impose a cost to the manipulating parasite. For natural selection to maintain or favour active hitch-hiking as a transmission strategy alternative to manipulation, the cost must not exceed the cost associated with manipulation, everything else being equal. Microphallidae sp. no. 15 might fulfil this condition because no specific cercarial behaviour, e.g. governed by presumably costly tactisms, appears to be needed in order to bring this parasite into contact with manipulated gammarids. Moreover, for evolution to maintain/favour hitch-hiking as an alternative strategy of transmission, the hitch-hiker cannot afford to increase the mortality rate of manipulated hosts significantly (see Thomas et al., 1998a,b). And since M. subdolum is a potent mortality agent of at least corophiid amphipods 
(Mouritsen and Jensen, 1997; Meissner and Bick, 1997, 1999), this species appears to be poorly adapted for hitchhiking.

In their behaviour experiment, Thomas et al. (1997) found that $26 \%$ of the hitch-hiker cercariae were swimming more than $2 \mathrm{~cm}$ above the bottom. Considering that this proportion is about 0 and $62-75 \%$ for $M$. subdolum and Microphallidae sp. no. 15, respectively, in the present experiments, Thomas et al. (1997) may accidentally have worked with, for instance, a mixture of the two species. Microphallidae sp. no. 15 is known to be present along the French Mediterranean coast (Deblock, 1980), where Thomas et al. (1997) made their investigations. However, should Microphallidae sp. no. 15 for some reason have been absent during their study, an alternative explanation for the discrepancy between our findings regarding the behaviour of $M$. subdolum, could be that subpopulations of $M$. subdolum in north and south Europe express different transmission strategies.

\section{Acknowledgements}

The work was supported by grants from The Carlsberg Foundation (Denmark), The Danish Natural Science Research Council (Denmark) and the Marsden Foundation (New Zealand). I also wish to thank S. Chinho for his effort in the laboratory and R. Poulin and referees who made useful comments on an earlier draft.

\section{References}

Combes, C., 1991. Ethological aspects of parasite transmission. Am. Nat. 138, 866-80.

Deblock, S., 1980. Inventaire des trématodes larvaires parasites des mollusques Hydrobia (prosobranches) des côtes de France. Parassitologia 22, $1-105$.

Dobson, A.P., 1988. The population biology of parasite-induced changes in host behaviour. Q. Rev. Biol. 63, 139-65.

Lafferty, K.D., 1999. The evolution of trophic transmission. Parasitol. Today $15,111-5$

Lafferty, K.D., Morris, K., 1996. Altered behaviour of parasitized killifish increases susceptibility to predation by bird final hosts. Ecology 77, $1390-7$.
Lafferty, K.D., Thomas, F., Poulin, R., 2000. Evolution of host phenotype manipulation by parasites and its consequences. In: Poulin, R., Morand, S. (Eds.), Evolutionary Biology of Host-Parasite Relationships: Theory Meets Reality. Elsevier, Amsterdam, pp. 117-27.

Meissner, K., Bick, B., 1997. Population dynamics and ecoparasitological surveys of Corophium volutator in coastal waters in the Bay of Mecklenburg (southern Balthic Sea). Dis. Aquat. Org. 29, 169-79.

Meissner, K., Bick, A., 1999. Mortality of Corophium volutator (amphipoda) caused by infestation with Maritrema subdolum (digenea, microphallidae) - laboratory studies. Discuss. Aquat. Organ. 35, 47-52.

Moore, J., Gotelli, N.J., 1990. Phylogenetic perspective on the evolution of altered host behaviours: a critical look at the manipulation hypothesis. In: Barnard, C.J., Behnke, J.M. (Eds.), Parasitism and Host Behaviour. Taylor \& Francis, London, pp. 193-229.

Mouritsen, K.N., Jensen, K.T., 1997. Parasite transmission between softbottom invertebrates: temperature mediated infection rates and mortality in Corophium volutator. Mar. Ecol. Prog. Ser. 151, 123 34.

Mouritsen, K.N., Jensen, T., Jensen, K.T., 1998. Parasites on an intertidal Corophium-bed: factors determining the phenology of microphallid trematodes in the intermediate host populations of the mud-snail Hydrobia ulvae and the amphipod Corophium volutator. Hydrobiologia 355, 61-70.

Poulin, R., 1994a. Meta-analysis of parasite-induced behavioural change. Anim. Behav. 48, 137-46.

Poulin, R., 1994b. The evolution of parasite manipulation of host behaviour: a theoretical analysis. Parasitology 109, S109-18.

Poulin, R., 1995. 'Adaptive' changes in the behaviour of parasitized animals: a critical review. Int. J. Parasitol. 25, 1371-83.

Poulin, R., Steeper, M.J., Miller, A.A., 2000. Non-random patterns of host use by the different parasite species exploiting a cockle population. Parasitology 121, 289-95.

Prokofyev, V.V., 1997. Behavioral responses of cercariae of intertidal trematoda Cryptocotyle sp. (heterophydidae) and Maritrema subdolum (microphallidae) to light. Zool. Zhur. 76, 275-80.

Thomas, F., Mete, K., Helley, S., Santalla, F., Verneau, O., De Meeus, T., Cezilly, F., Renaud, F., 1997. Hitch-hiker parasites or how to benefit from the strategy of another parasite. Evolution 51, 1316-8.

Thomas, F., Renaud, F., Poulin, R., 1998a. Exploitation of manipulators: 'hitch-hiking' as a parasite transmission strategy. Anim. Behav. 56, 199-206.

Thomas, F., Villa, M., Montoliu, I., Santalla, F., Cezilly, F., Renaud, F., 1998b. Analyses of a debilitating parasite (Microphallus papillorobustus, trematoda) and its 'hitch-hiker' parasite (Maritrema subdolum, trematoda) on survival of their intermediate host (Gammarus insensibilis, amphipoda). J. Helminthol. Soc. Washington 56, 1-5.

Thomas, F., Poulin, R., Renaud, F., 1998c. Nonmanipulative parasites in manipulated hosts: 'hitch-hikers' or simply 'lucky passengers'? J. Parasitol. 84, 1059-61. 